\title{
Enhancement of Cobalt Concentration Supported on Mesoporous Silica towards the Characteristics and Activities of Catalysts for the Conversion of Waste Coconut Oil into Gasoline and Diesel Oil
}

\author{
Wega Trisunaryanti*, Triyono, Nugroho Raka Santoso, Savitri Larasati, \\ Cahyarani Paramesti, and Dyah Ayu Fatmawati* \\ Department of Chemistry, Faculty of Mathematics and Natural Sciences, Universitas Gadjah Mada, \\ Sekip Utara, Yogyakarta 55281, Indonesia
}

${ }^{*}$ Corresponding author:

email:wegats@ugm.ac.id;

dyah.ayu.fatmawati@mail.ugm.ac.id ${ }^{* *}$

Received: April 23, 2020

Accepted: July 11, 2020

DOI: $10.22146 /$ ijc.55633

\begin{abstract}
The analysis of the effect of cobalt concentration supported on mesoporous silica (MS) has been evaluated. This study was aimed to observe the physical and chemical characteristics of the catalysts, and also to study the catalytic activity and its selectivity towards gasoline and diesel oil products in the hydrocracking process of waste coconut oil. The MS was produced using Lapindo mud, where the CTAB was used as the mesopore templating agent. The Co/MS catalyst was prepared by the wet impregnation method with various concentrations of Co. The characterization of the catalyst includes silica purity test by XRF, determination of Co content by AAS, the crystallinity by XRD, the catalyst porosity by SAA, physical pore structure by SEM and TEM, and total acidity by the gravimetric method using $\mathrm{NH}_{3}$ base vapor adsorption. The hydrocracking was carried out in a hydrocracking reactor using various concentrations of Co/MS catalysts with the ratio of catalyst/feed $=1 / 50$. The products of the hydrocracking process were liquid, coke, and gas. The composition of the hydrocracking liquid products was analyzed by GC-MS. Based on the results of the catalytic activity test, it was concluded that the Co(1)/MS catalyst, which had the highest acidity, showed the best catalyst selectivity towards gasoline and diesel fractions.
\end{abstract}

Keywords: cobalt; CTAB; hydrocracking; Lapindo mud; mesoporous silica; waste coconut oil

\section{- INTRODUCTION}

In the $21^{\text {st }}$ century, many issues concerning energy sustainability, environmental problems, and rising fuel prices have been surfacing. Conventional fuels are known for polluting the air due to emissions of sulfur dioxides, carbon dioxides, particulate matter, and other gases [1]. Due to worldwide environmental concern and the increasing fuel demand, conventional energy sources are being steadily substituted by available renewable sources of liquid fuels such as biofuels, alcohol, and vegetable oil. The transformation of vegetable oil to biofuel offers environmental benefits since they are renewable, readily available, have low sulfur and aromatics, and are biodegradable. Similar to fossil fuels derived from petroleum, vegetable oil can be thermochemically converted to biofuels such as unfinished gasoline, kerosene, and biodiesel [2].

However, the cost of feedstock and limited availability of edible vegetable oils are critical issues for biofuel production. The exploit of Waste Cooking Oil (WCO) as biofuel feedstock reduces the cost of biofuel production since the feedstock costs constitute approximately $70-95 \%$ of the overall cost of biofuel production [3]. There are several conversion methods of vegetable oils into biofuels, such as thermal cracking, catalytic cracking, and hydrocracking [4-6].

Thermal cracking, a conversion technique of vegetable oil to biofuel, is performed under conditions of high temperature and high pressure of hydrogen in the absence of a catalyst. These conditions cause the cost 
of thermal cracking to be relatively high. Moreover, a large amount of gas and naphtha produced during the process is of relatively low quality due to over cracking [7]. Alternatively, the catalytic cracking process in the absence of high pressure of hydrogen increases a significant amount of desirable olefinic and aromatic compounds in the biofuels, and coke depositing on the catalyst. Hydrocracking is the combination of catalytic cracking and hydrogenation process. Properties of the hydrocracking products, i.e., gasoline or kerosene, showed improved oxidation stability and higher cetane numbers [8]. Hydrocracking reaction progress through a dual functional mechanism that requires two different types of catalytic sites. These sites are the acidic support that promotes cracking and isomerization and also the metallic sites that promote dehydrogenation, hydrogenation, and undesirable hydrogenolysis. In order to synthesize an optimal hydrocracking catalyst, a suitable balance between acid and metal site density has to be maintained [9].

Research on mesoporous material has been highly developed due to its superiority in various applications such as catalysts, adsorbents, and others. Mesostructure has large surface area sizes allowing for large-scale diffusion and adsorption of molecules in various applications [10]. The main components in the formation of mesoporous materials can be in the form of silica, alumina, and carbon. One of the basic components favored compared to others is silica because it is thermally stable, non-hazardous, and cheap [11]. Silica can be found in natural materials including the Lapindo mud in Sidoarjo, East Java, Indonesia. Lapindo mud can be used as the main potential source in the synthesis of mesoporous material due to high silica content (>47\%) [12].

One important factor in mesoporous material synthesis is the selection of templates. The main requirement for a template is to have an amphiphilic character and mesostructure-forming properties [13]. Commonly used types of mesostructure templates are cationic and neutral surfactants. A cationic surfactant such as CTAB (Cetyl Trimethyl Ammonium Bromide) is often used in MCM-41 synthesis [14-15].

MS contains pure silica material that only has a weak Lewis acid site content and has no Brønsted acid site, making it difficult to be used directly as a catalyst and adsorbent. The Lewis acid site will increase if a transition metal is included in the MS structure. Improving the dispersion of the metal nanoparticles can increase the activity of the catalyst. The stability of the catalyst depends on the dispersion of the metal and the interaction between the metallic phase and the support [16-17]. The metals that are usually used in the catalyst are the transition metals such as $\mathrm{Co}, \mathrm{Ni}, \mathrm{Cr}, \mathrm{Fe}$, etc.

In a previous study, cobalt and molybdenum metal were used as the catalyst support on mesoporous silicaalumina (MSA) and showed that the cobalt supported catalyst had the highest liquid conversion of a-cellulose oil pyrolysis compared to molybdenum in the hydrocracking process [18]. The nature and the dispersion of cobalt are the key factors in determining the activity and the selectivity of the supported catalyst.

The current research studies the synthesis of cobalt metal supported mesoporous silica catalyst using various concentrations of cobalt and also its application for the conversion of waste coconut oil. The correlation of the catalyst characteristics to its activity and selectivity is also reported.

\section{- EXPERIMENTAL SECTION}

\section{Materials}

Materials used in this research were Lapindo mud, hydrochloric acid ( $\mathrm{HCl}$, Fluka $37 \%$ p.a), sodium hydroxide $(\mathrm{NaOH}$, Merck p.a), cetyltrimethylammonium bromide (CTAB), cobalt(II) nitrate hexahydrate $\left(\mathrm{Co}\left(\mathrm{NO}_{3}\right)_{2} \cdot 6 \mathrm{H}_{2} \mathrm{O}\right)$, silver nitrate $\left(\mathrm{AgNO}_{3}\right)$, ammonia solution $\left(\mathrm{NH}_{3}\right.$ sol $\left.25 \%\right), \mathrm{N}_{2}$ gas, $\mathrm{H}_{2}$ gas, demineralized water, Whatman filter paper No. 42 and 41 , universal pH indicator strips (Merck), and waste coconut oil.

\section{Instrumentation}

The purity of synthesized silica and the chemical content of the Lapindo mud were analyzed by X-ray Fluorescence (XRF, Analytical MiniPal 4). X-ray Diffractometer (XRD, Philips X-pert Powder Diffractometer) was used to observe the crystallinity of the catalysts. The amount of metal content of all samples was determined using Atomic Absorption Spectroscopy 


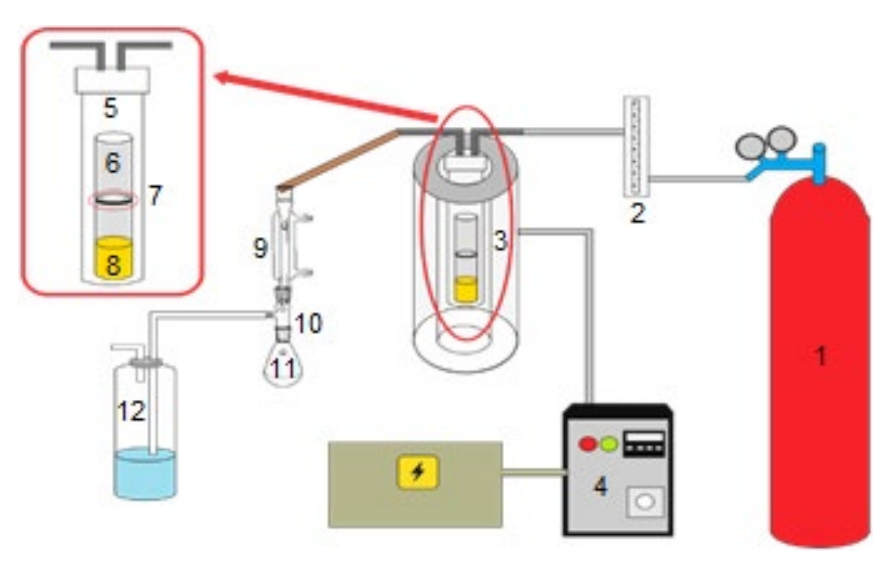

Fig 1. Schematic illustration of the hydrocracking reactor (1) gas tank, (2) flow meter, (3) reactor, (4) thermocouple, (5) feed vessel, (6) catalyst vessel, (7) iron gauze 200 mesh, (8) oil feed vessel, (9) Liebig condenser, (10) connector, (11) hearth flask, (12) gas trapper

(AAS, Perkin Elmer 3110). The surface parameters (surface area, pore-volume, and pore diameter) of the samples were analyzed using the Surface Area Analyzer (SAA, St 2 on NOVA touch $4 \mathrm{LX}$ ). The surface morphology of the catalyst was analyzed using a Scanning Electron Microscope (SEM, JMS-6510LA). The pore images were taken using a Transmission Electron Microscope (TEM, JEM-1400). The liquid products obtained from hydrocracking of waste coconut oil were analyzed using Gas Chromatography-Mass Spectrophotometer (GC-MS, Shimadzu QP2010S).

\section{Procedure}

\section{Silica extraction from Lapindo mud}

Based on our XRF result, the Lapindo mud contained $45.49 \%$ of $\mathrm{SiO}_{2}, 17.24 \%$ of $\mathrm{Al}_{2} \mathrm{O}_{3}, 8.19 \%$ of $\mathrm{Fe}_{2} \mathrm{O}_{3}$, and $29.08 \%$ of other compounds. The Lapindo mud was cleaned and washed with demineralized water and then dried. Afterwards, the Lapindo mud was sieved up to 100 mesh. Later, $100 \mathrm{~g}$ of Lapindo mud was refluxed with $400 \mathrm{~mL}$ of $6 \mathrm{M} \mathrm{HCl}\left(90^{\circ} \mathrm{C}, 5 \mathrm{~h}\right)$. Afterwards, the sample was filtered and washed by demineralized water until it was free from $\mathrm{Cl}$. The filtrate was dried at $100^{\circ} \mathrm{C}$ for $24 \mathrm{~h}$. The residue was then refluxed with $400 \mathrm{~mL}$ of $6 \mathrm{M} \mathrm{NaOH}$ $\left(90{ }^{\circ} \mathrm{C}, 5 \mathrm{~h}\right)$. The refluxed mud was then filtered using Whatman 42 , and the $\mathrm{Na}_{2} \mathrm{SiO}_{3}$ solution was obtained. After that, $\mathrm{Na}_{2} \mathrm{SiO}_{3}$ solution was added with $3 \mathrm{M} \mathrm{HCl}$ (until the
$\mathrm{pH}$ reaches 8) and was settled overnight until the white gel formed. The white gel that was formed was then filtered and dried at $100{ }^{\circ} \mathrm{C}$ overnight. The extracted silica was characterized by XRF and XRD.

\section{Synthesis of mesoporous silica (MS)}

The ratio of silica/CTAB used in this research was $\sim 2$. Three point nine hundred and seventy five grams of $\mathrm{CTAB}$ was diluted in $65 \mathrm{~mL}$ demineralized water at $40{ }^{\circ} \mathrm{C}$ (under stirring). Meanwhile, $7.5 \mathrm{~g}$ of synthesized silica was diluted in $200 \mathrm{~mL}$ of $1.5 \mathrm{M} \mathrm{NaOH}$, forming the $\mathrm{Na}_{2} \mathrm{SiO}_{3}$ solution. The $\mathrm{Na}_{2} \mathrm{SiO}_{3}$ solution was dropped carefully to the CTAB solution until it was homogenous. Afterwards, $3 \mathrm{M} \mathrm{HCl}$ was added to the solution until the $\mathrm{pH}$ became 10 and then the solution was settled for $4 \mathrm{~h}$. After that, the solution was put in the autoclave $\left(100^{\circ} \mathrm{C}\right.$, $24 \mathrm{~h}$ ). The white solids were then washed using demineralized water until the $\mathrm{pH}$ became neutral, then dried at $80^{\circ} \mathrm{C}$ for $24 \mathrm{~h}$. The formed solids were calcined at $550{ }^{\circ} \mathrm{C}$ for $5 \mathrm{~h}\left(10^{\circ} \mathrm{C} \mathrm{min}{ }^{-1}\right)$. The mesoporous silica was analyzed using XRD, AAS, and SAA.

\section{Preparation of Co/MS via wet-impregnation}

$\mathrm{Co} / \mathrm{MS}$ catalysts were prepared by impregnation method. An aqueous solution containing $0.00494 \mathrm{~g}$ of $\mathrm{Co}\left(\mathrm{NO}_{3}\right)_{2} \cdot 6 \mathrm{H}_{2} \mathrm{O}$ was mixed with $0.5 \mathrm{~g}$ of MS in a beaker glass for a ratio of $1 \mathrm{wt} . \%$. The solution was stirred until homogenous and kept overnight. The Co concentration was varied at 1,3 , and $5 \mathrm{wt} . \%$ towards the MS, which were subsequently mentioned as $\mathrm{Co}(1) / \mathrm{MS}, \mathrm{Co}(2) / \mathrm{MS}$, and $\mathrm{Co}(3) / \mathrm{MS}$. The solution was evaporated and dried by using an oven at $100^{\circ} \mathrm{C}$ overnight. The dried mixture was then calcined with flowing $\mathrm{N}_{2}$ gas at flow rate of $20 \mathrm{~mL}$ $\mathrm{min}^{-1}$, and temperature of $500{ }^{\circ} \mathrm{C}$ for $2 \mathrm{~h}$. After that, the reduction process was conducted under $\mathrm{H}_{2}$ gas at flow rate of $20 \mathrm{~mL} \mathrm{~min}^{-1}$ for $3 \mathrm{~h}$ to remove oxygen from the $\mathrm{Co} / \mathrm{MS}$. The produced catalysts were analyzed using $\mathrm{XRD}, \mathrm{AAS}$, and SAA.

The acidity of the catalysts was tested by the gravimetric method using $\mathrm{NH}_{3}$ gas as the basic adsorbate. Point zero five grams of catalyst was placed in a porcelain crucible and put into a desiccator. The desiccator was vacuumed and flowed with $\mathrm{NH}_{3}$ vapor for $24 \mathrm{~h}$. After that, the sample was taken out from the 
desiccator and weighed as porcelain crucible with sample after adsorption. The acidity of the catalyst was determined using the following Eq. (1).

$$
\operatorname{Acidity}(\mathrm{mmole} / \mathrm{g})=\frac{\mathrm{W}_{2}-\mathrm{W}_{1}}{\left(\mathrm{~W}_{1}-\mathrm{W}_{0}\right) \times \mathrm{MWNH}_{3}} \times 1000
$$

where, $\mathrm{W}_{0}=$ weight of empty porcelain crucible $(\mathrm{g}) ; \mathrm{W}_{1}=$ weight of porcelain crucible + sample before adsorption (g); $\mathrm{W}_{2}=$ weight of porcelain crucible + sample after adsorption (g); and $\mathrm{MW}=$ molecular weight of $\mathrm{NH}_{3}\left(\mathrm{~g} \mathrm{~mol}^{-1}\right)$

\section{Catalytic activity test}

The weight ratio of catalyst/waste coconut oil that was used to test the catalytic activity was 1:50(1 $\mathrm{g}$ of catalyst; $50 \mathrm{~g}$ of feed). The feed and catalyst were put in a container, and then the container was put into the conversion reactor. Afterwards, the sample was heated at $450{ }^{\circ} \mathrm{C}$ with increasing temperature of $10^{\circ} \mathrm{C} \mathrm{min}^{-1}$ and $\mathrm{H}_{2}$ gas with a flow rate of $15 \mathrm{~mL} \mathrm{~min}{ }^{-1}$ inside the flask. The schematic illustration of the hydrocracking reactor is shown in Fig. 1. The result of the cracking process was then determined as its liquid conversion percentage (\%) using Eq. (2).

Liquid Product $(\%)=\frac{\mathrm{Mc}}{\mathrm{Mu}} \times 100 \%$

Coke Formation $(\%)=\frac{\mathrm{Mk}}{\mathrm{Mu}} \times 100 \%$

Residue Formation (\%) $=\frac{\mathrm{Mr}}{\mathrm{Mu}} \times 100 \%$

Gas Product $(\%)=\frac{\mathrm{Mu}-(\mathrm{Mc}+\mathrm{Mk})}{\mathrm{Mu}} \times 100 \%$

Total Conversion $(\%)=\frac{\mathrm{Mu}-\mathrm{Mr}}{\mathrm{Mu}} \times 100 \%$

where, $\mathrm{Mc}=$ liquid product mass ( $\mathrm{g}$ ); $\mathrm{Mk}=$ coke mass $(\mathrm{g})$; $\mathrm{Mr}=$ residue mass $(\mathrm{g})$; and $\mathrm{Mu}=$ mass of waste coconut oil (g)

The hydrocracking products were analyzed by GCMS to determine the compound content in the liquid. The chromatogram result from the analysis of liquid product represented as the relative percentage for each compound contained in the liquid product. The selectivity percentage of the gasoline and diesel fraction on liquid oil waste product was determined using Eq. (3).

Gasoline Fraction $(\%)=\frac{\mathrm{Ra}}{\mathrm{Rx}} \times \mathrm{Rt}(\%)$

Diesel Fraction $(\%)=\frac{\mathrm{Rb}}{\mathrm{Rx}} \times \mathrm{Rt}(\%)$ where, $\mathrm{Ra}=\mathrm{C}_{5}-\mathrm{C}_{12} \mathrm{GC}$ area (\%); $\mathrm{Rb}=\mathrm{C}_{13}-\mathrm{C}_{17} \mathrm{GC}$ area (\%); $\mathrm{Rx}=$ Total relative (\%); $\mathrm{Rt}=$ Liquid product conversion (\%); GF = Gasoline Fraction; and DF = Diesel Fraction

\section{- RESULTS AND DISCUSSION}

\section{Silica Extraction}

Based on the XRF analysis results, silica was proven to be the main component in the sample with an average content of $96.9 \%$, which indicates that the silica extracted from the Lapindo mud has high purity. this result was also supported by the XRD data as shown in Fig. 2, which shows the amorphous silica phase in the range of $15^{\circ}<2 \theta<30^{\circ}$. However the purity of the silica does not reach $100 \%$ due to the presence of impurities such as iron oxide $(0.15 \%)$ and other compounds (2.99\%). One hundred percent purity is very difficult to obtain from the extraction process; even more so, if the silica source comes from nature.

\section{Catalysts Characterization}

The XRD pattern of MS, Co(1)/MS, Co(2)/MS, and $\mathrm{Co}(3) / \mathrm{MS}$ are shown in Fig. 3. As expected, mesoporous silica did not show any sharp diffraction peaks consistent with the amorphous structure of the support. The broad peak at $15^{\circ}<2 \theta<30^{\circ}$ was observed for all catalysts, corresponding to the amorphous silica phase. The broad peak intensity of $\mathrm{Co}(1) / \mathrm{MS}, \mathrm{Co}(2) / \mathrm{MS}$, and $\mathrm{Co}(3) / \mathrm{MS}$ decreased with increasing cobalt concentration [19]. This

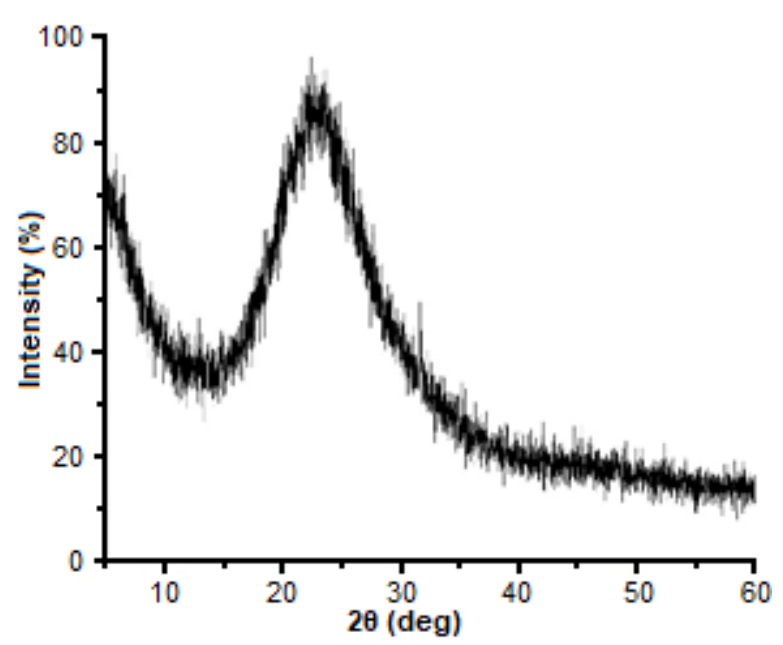

Fig 2. Wide-angle XRD of extracted silica 


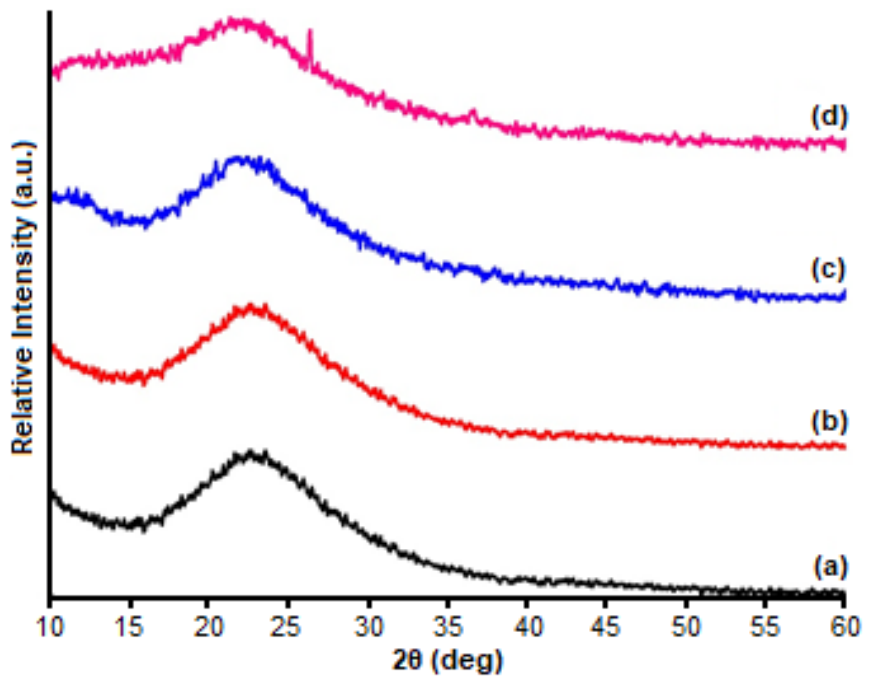

Fig 3. Wide-angle XRD pattern obtained from (a) MS, (b) $\mathrm{Co}(1) / \mathrm{MS}$, (c) $\mathrm{Co}(2) / \mathrm{MS}$, (d) $\mathrm{Co}(3) / \mathrm{MS}$

indicates that the impregnation of metal slightly reduced the amorphous area. This is because the surface of the mesoporous silica is attended by new species that should give rise to new crystalline peaks. However, there was not much metal in material, so this effect does not appear.
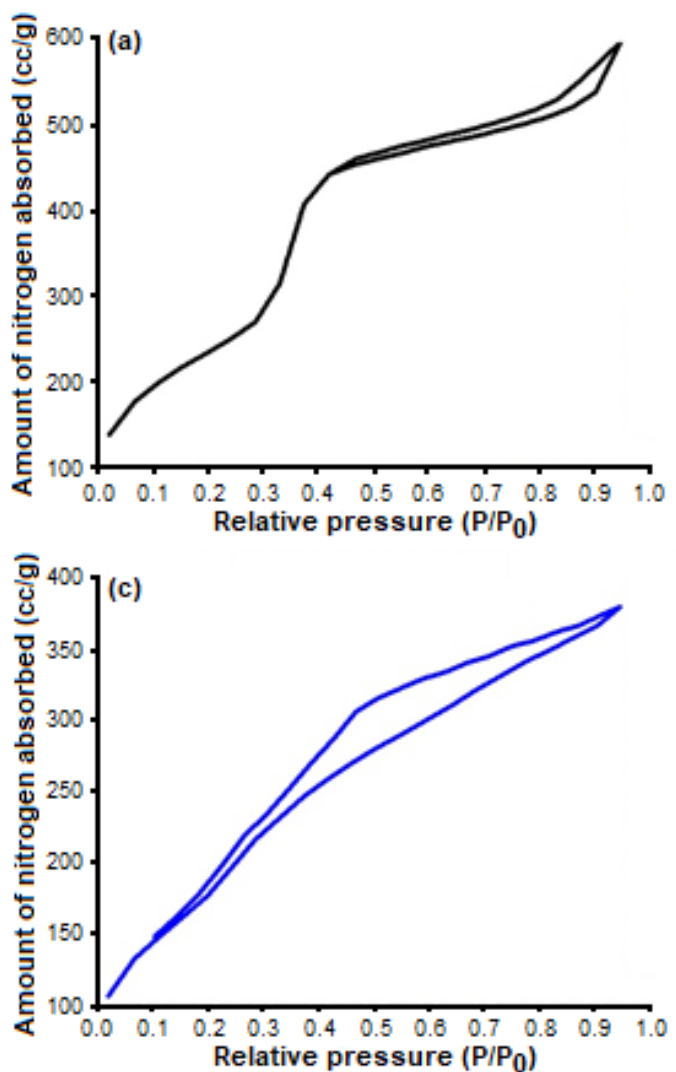

Fig 4. $\mathrm{N}_{2}$ gas adsorption-desorption isotherm of (a) MS, (b) Co(1)/MS, (c) Co(2)/MS, and (d) Co(3)/MS
As seen in Fig. 3, Co(1)/MS, Co(2)/MS, and Co(3)/MS do not display significant peak of cobalt diffraction pattern, unlike high cobalt loaded catalysts. This can be attributed to the low content of cobalt metal species. Although the presence of cobalt metal in MS could not be proven in XRD analysis, the AAS analysis showed that there was cobalt metal content carried in MS.

The $\mathrm{N}_{2}$ adsorption-desorption isotherm of MS and cobalt supported-catalysts are shown in Fig. 4. The isotherm of MS in Fig. 4(a) exhibits a type IV isotherm with $\mathrm{H} 4$ hysteresis according to the IUPAC classification. After loading of cobalt, the isotherm shades of the catalyst with different cobalt content were relatively similar to MS. This shows that the impregnation of cobalt did not give significant changes in the mesoporous structure of the catalyst. The hysteresis type of the cobalt supported catalysts were considered as the H4 type, which showed relatively uniform wormhole-like pores [20] as seen in the TEM image that will be displayed later.
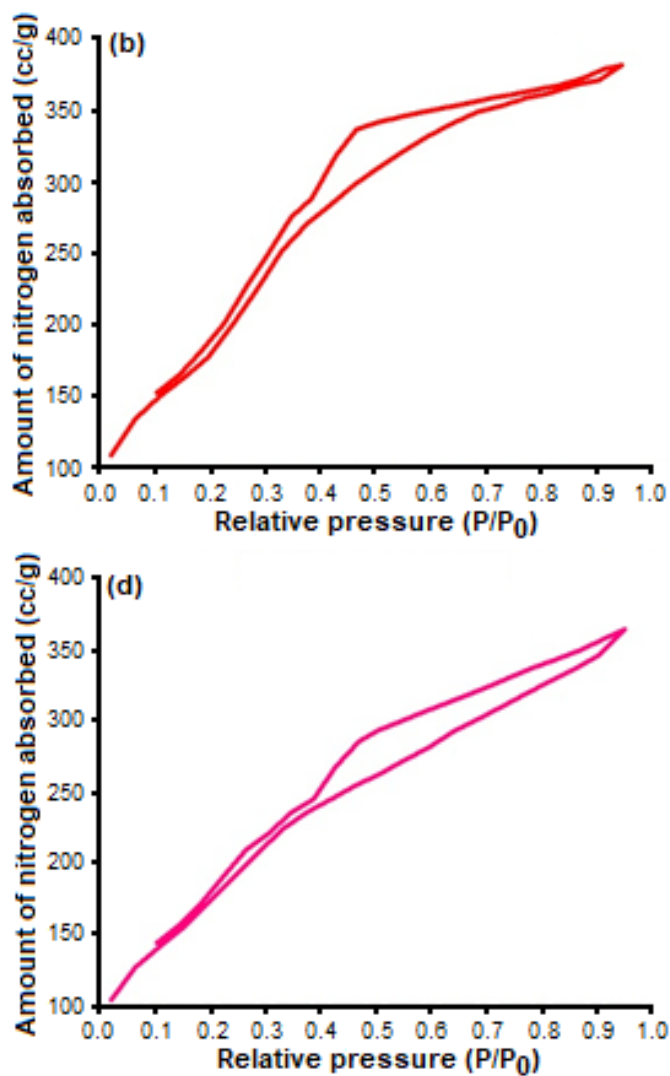
In this study, capillary condensation of $\mathrm{Co}(1) / \mathrm{MS}$, $\mathrm{Co}(2) / \mathrm{MS}$, and $\mathrm{Co}(3) / \mathrm{MS}$ were shifted to lower relative pressure with a shoulder on the desorption branch. The presence of the shoulder on the desorption branch of the cobalt supported catalysts in Fig. 4(b), (c), and (d) at relative pressure $\left(\mathrm{P} / \mathrm{P}_{0}\right)$ of around 0.45 , can be attributed to partial pore blockage due to the presence of the metal cobalt species in the aperture of the pores that cause a decrease in the specific surface area. This is known as the cavitation phenomenon.

Pore distribution of porous materials was calculated using the $\mathrm{BJH}$ method. In this research, the $\mathrm{BJH}$ method was used to calculate the pore distributions from the experimental isotherm using the Kelvin mode of pore filling. This method can be applied to the mesopore and all macropore size range. The size of the pore distribution peak indicates the pore size average. The narrow pore distribution peak means that the pore size is homogenous.

As seen in Fig. 5, MS has the narrowest peak among the other catalysts. This indicates that MS has the most homogenous pore size. Meanwhile, the peak distribution of the impregnated MS shows a less narrow peak, which means that the impregnated MS has less homogenous pore distribution compared to MS. The impregnation of cobalt metal into MS does affect the homogeneity of the pore distribution, which can be seen from the peak of $\mathrm{Co}(1) / \mathrm{MS}, \mathrm{Co}(2) / \mathrm{MS}$, and $\mathrm{Co}(3) / \mathrm{MS}$, in which the peak intensity continually decreased. All of the cobalt supported catalysts showed unimodal pore distribution, where it still increases at the smaller pore size. This suggests that there may be partial pore blockage or deposition of cobalt particles against the internal silica walls and/or at the pore apertures. This is also proven by the decrease of total pore volume, where the total pore volume of $\mathrm{MS}>\mathrm{Co}(1) / \mathrm{MS}>\mathrm{Co}(2) / \mathrm{MS}>\mathrm{Co}(3) / \mathrm{MS}$ as shown in Table 1. Although their pore size distributions differ in homogeneity, the average pore size obtained by all catalysts was relatively similar to each other so their ability to absorb molecules contained in the substrate was also relatively similar.

The actual metal content of the impregnated MS that had been determined using AAS were slightly different from the loaded amount. This can happen possibly because some of the metal was left on the glassware that was used in the impregnation process, or it can also be caused by the uneven dispersion of the metal that caused unevenly distributed metal on the surface of the catalyst.

The addition of metal can give support to the acid sites in the catalyst system through the Lewis acid site. The cobalt metal contained in the catalyst sample can affect the acidity of the catalyst considering the empty $4 p$ orbital that acts as the Lewis acid site. The acidity of the catalyst with higher metal content should also be higher. All data show a relationship between the loaded metal and the acidity of the catalyst, but there is an anomaly in this study. The Co(1)/MS had the highest acidity value

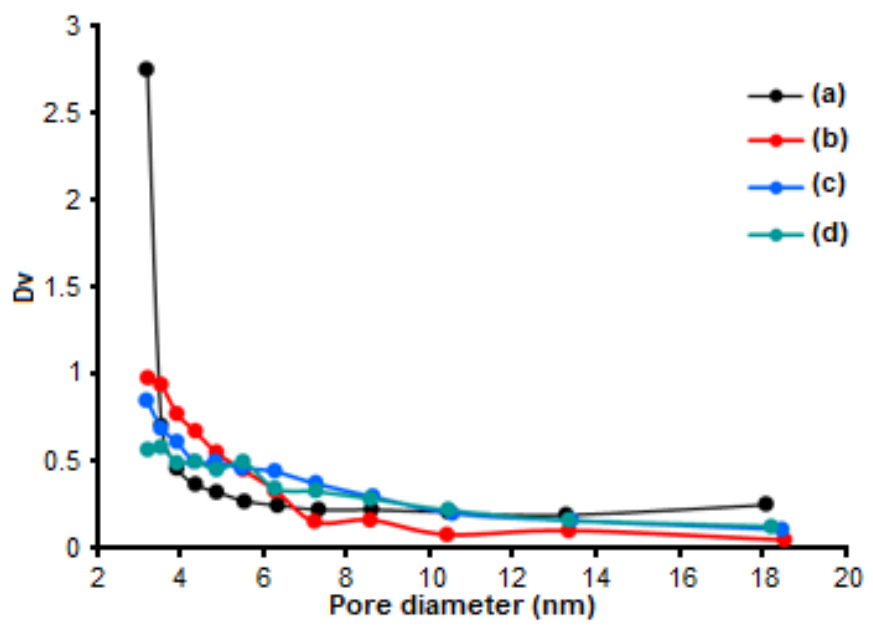

Fig 5. Pore size distribution (BJH desorption) of (a) MS, (b) $\mathrm{Co}(1) / \mathrm{MS}$, (c) $\mathrm{Co}(2) / \mathrm{MS}$, and (d) $\mathrm{Co}(3) / \mathrm{MS}$

Table 1. Summary of the textural properties of the catalysts

\begin{tabular}{lccccc}
\hline $\begin{array}{c}\text { Catalyst } \\
\text { samples }\end{array}$ & $\begin{array}{c}\text { Total pore } \\
\text { volume }(\mathrm{cc} / \mathrm{g})\end{array}$ & $\begin{array}{c}\text { Average pore } \\
\text { diameter }(\mathrm{nm})\end{array}$ & $\begin{array}{c}\text { BJH surface area } \\
\left(\mathrm{m}^{2} \mathrm{~g}^{-1}\right)\end{array}$ & $\begin{array}{c}\text { Cobalt } \\
\text { content }(\%)\end{array}$ & $\begin{array}{c}\text { Acidity } \\
\left(\mathrm{mmol} \mathrm{g}^{-1}\right)\end{array}$ \\
\hline $\mathrm{MS}$ & 0.93 & 3.28 & 291 & 0.00 & 13.24 \\
$\mathrm{Co}(1) / \mathrm{MS}$ & 0.60 & 3.27 & 233 & 0.95 & 17.94 \\
$\mathrm{Co}(2) / \mathrm{MS}$ & 0.59 & 3.28 & 224 & 1.39 & 13.91 \\
$\mathrm{Co}(3) / \mathrm{MS}$ & 0.57 & 3.28 & 192 & 5.26 & 15.36 \\
\hline
\end{tabular}


because the $\mathrm{NH}_{3}$ gases was completely absorbed on the surface of the catalyst where the metals were well dispersed, while for $\mathrm{Co}(2) / \mathrm{MS}$ and $\mathrm{Co}(3) / \mathrm{MS}$, the $\mathrm{NH}_{3}$ gases were not completely adsorbed by the metal, possibly due to agglomeration or the pore blocking of the metal. As seen in Table 1, the order of acidity is Co(1)/MS > $\mathrm{Co}(3) / \mathrm{MS}>\mathrm{Co}(2) / \mathrm{MS}>\mathrm{MS}$. It was predicted that the hydrocarbon product would follow the acidity content of the catalyst because acidic sites have a function to help the cracking process of large molecules into smaller molecules.

The morphology and the orderliness of MS and Co(1)/MS were analyzed using SEM. As seen in Fig. 6, the MS pores are shaped like slit-like pores. The SEM image of MS also shows that it consists of aggregates of uniform sphere-like particles but not too ordered. The pores formation on MS material was affected by the micelle shape from the CTAB templates that were used. The synthesized MS material only showed the slit-like pores that were affected by the calcination process and did not fully degrade the CTAB template, leaving the remaining CTAB molecules in the MS. Furthermore, the SEM image of $\mathrm{Co}(1) / \mathrm{MS}$ does not show any significant changes. However, it can be seen that the pores of the catalyst were slightly reduced, indicating that the cobalt metals were filling the pores of the catalyst.

Fig. 7 shows TEM images of $\mathrm{Co}(1) / \mathrm{MS}$ before and after the hydrocracking process. The TEM result indicated that before hydrocracking, $\mathrm{Co}(1) / \mathrm{MS}$ had a wormhole-like pore structure. This result was similar to the TEM images of Co/MS that were synthesized in previous work [18]. Meanwhile, the TEM image of $\mathrm{Co}(1) / \mathrm{MS}$ after hydrocracking (coke) showed that there were no pores, indicating that the pores of the $\mathrm{Co}(1) / \mathrm{MS}$ were blocked by the carbon that were trapped inside the pores.
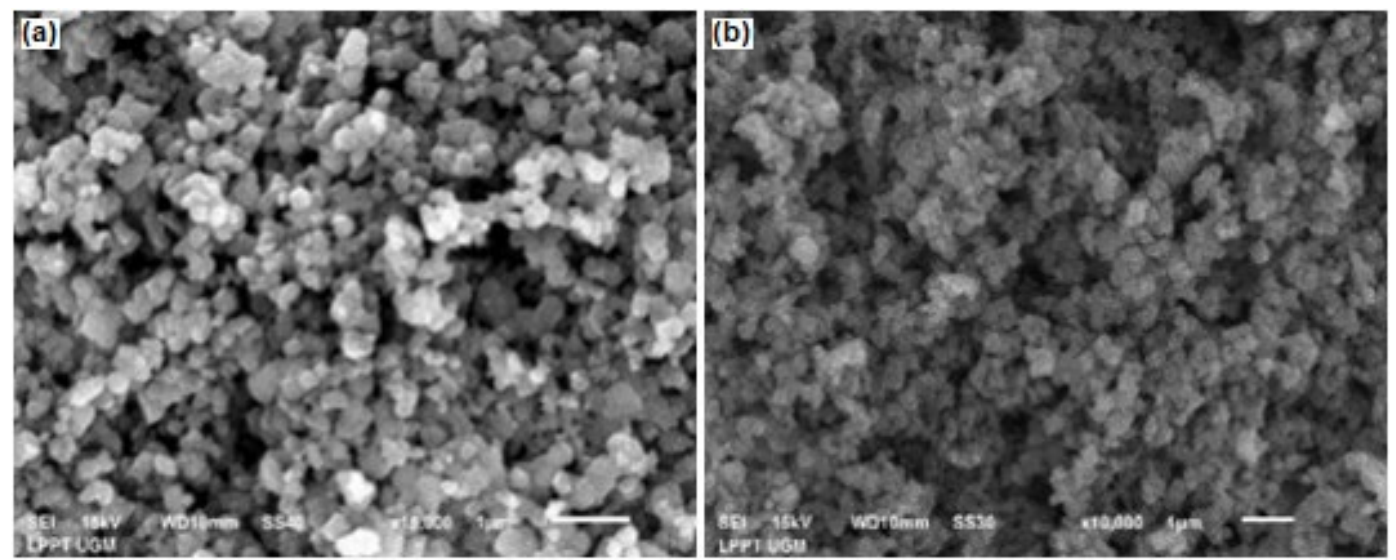

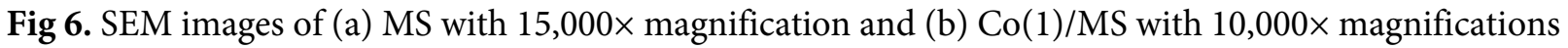
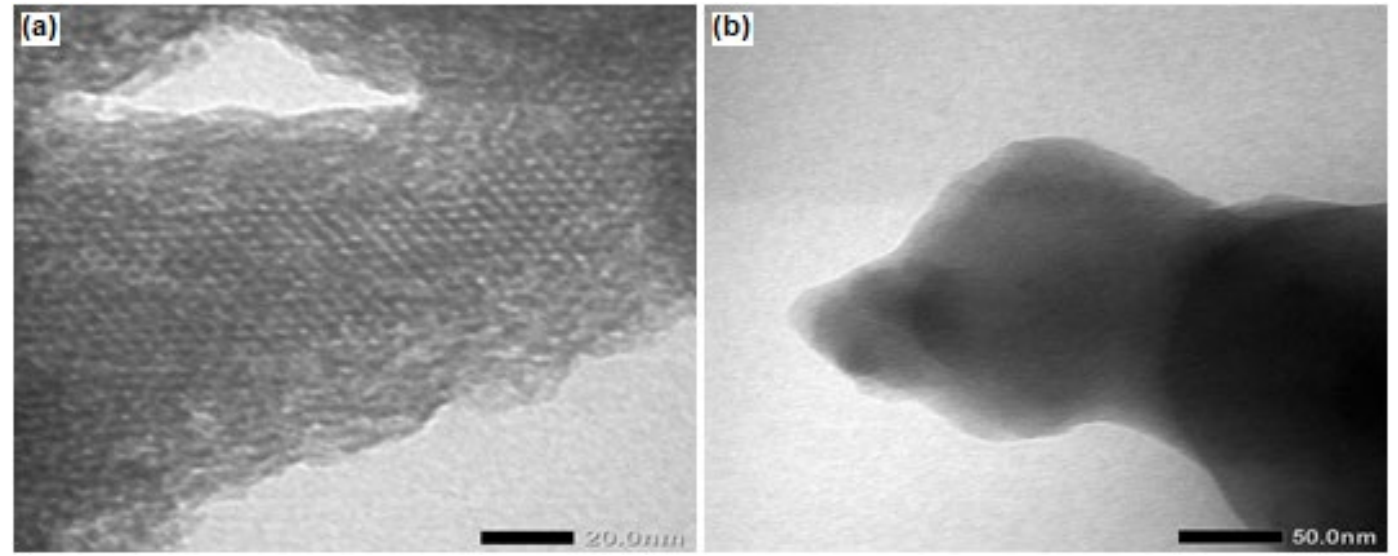

Fig 7. TEM images of Co(1)/MS (a) before and (b) after hydrocracking 


\section{Catalytic activity and selectivity test}

Waste coconut oil is a hydrocarbon compound with the carbon chain of $\leq \mathrm{C}_{18}$ that needs a catalyst with good catalytic activity in the cracking treatment. The cracking process in the current study was conducted using a fixed bed reactor with a temperature of $450^{\circ} \mathrm{C}$. As seen in Table 2 , the hydrocracking process produced three phases of product, namely liquid, gas, and coke fraction, along with leftover residues.

The results show that the order of the amount of liquid product is $\mathrm{Co}(2) / \mathrm{MS}>\mathrm{Co}(3)>\mathrm{Co}(1) / \mathrm{MS}$. This order follows the number of metal sites entrusted to MS. The more metals are loaded, the more d orbitals containing one electron are used as the electron place of hydrogen gas. This state facilitates the hydrogenation process.

It can be seen in Table 2 that higher amounts of metal impregnated to the MS relatively improves the conversion of the liquid product, except for the $\mathrm{Co}(3) / \mathrm{MS}$ catalyst. The $\mathrm{Co}(2) / \mathrm{MS}$ catalyst gave the highest conversion of the liquid product among the other catalysts because it had the optimal metal content in the catalyst. Meanwhile, the Co(3)/MS, which had the highest cobalt content, did not give the highest conversion of liquid product. This could happen possibly because the cobalt in the $\mathrm{Co}(3) / \mathrm{MS}$ dispersed in the inner surface of the MS, and the feed was not able to reach every metal inside the pores of the MS due to blocking from other metals in the same pore. Another possibility is the occurrence of sintering of the metals embedded in MS because of high hydrogen gas pressure. The liquid product from the hydrocracking process was analyzed by GC-MS to determine the compounds that were produced from the hydrocracking process of the waste coconut oil. The content of gasoline $\left(\mathrm{C}_{5}-\mathrm{C}_{12}\right)$, diesel $\left(\mathrm{C}_{13^{-}}\right.$ $\mathrm{C}_{17}$ ), and organic compound fractions contained in the liquid product of the hydrocracking process could be obtained from the peak area percentage of the GC-MS analysis result.

As seen in Table 3, it can be observed that the order of the total hydrocarbon products (gasoline and diesel fractions) is $\mathrm{Co}(1) / \mathrm{MS}>\mathrm{Co}(3) / \mathrm{MS}>\mathrm{Co}(2) / \mathrm{MS}$. This is based on the acidity value of the catalyst. The higher the acidity value, the easier the cracking process of the molecules [21]. The total of both gasoline and diesel fraction by $\mathrm{Co}(1) / \mathrm{MS}, \mathrm{Co}(3) / \mathrm{MS}$, and $\mathrm{Co}(2) / \mathrm{MS}$ catalyst were $64.85,57.18,56.67 \mathrm{wt} . \%$ respectively. Therefore, it can be concluded that the $\mathrm{Co}(1) / \mathrm{MS}$ catalyst with the highest acidity value had the highest selectivity towards the hydrocarbon fractions (gasoline and diesel).

\section{- CONCLUSION}

In this study, the preparation of catalysts via the wet-impregnation method was successfully applied for $\mathrm{Co} / \mathrm{MS}$, and the results showed that the impregnation of metals did not significantly change the texture of the catalyst, which agreed with XRD, BET, SEM, and TEM results. The $\mathrm{Co}(1) / \mathrm{MS}$ catalyst with the lowest Co content of $0.95 \%$ and highest acid sites of $17.94 \mathrm{mmol} \mathrm{g}^{-1}$ showed

Table 2. Hydrocracking conversion products of waste coconut oil

\begin{tabular}{cccccc}
\hline \multirow{2}{*}{ Catalyst } & \multicolumn{3}{c}{ Conversion (wt.\%) } & Residues & $\begin{array}{c}\text { Total conversion } \\
\text { (wt.\%) }\end{array}$ \\
\cline { 2 - 4 } & Liquid fraction & Gas fraction & Coke & & 99.10 \\
\hline Co(1)/MS & 75.97 & 23.79 & 0.24 & 0.90 & 99.41 \\
Co(2)/MS & 79.17 & 20.77 & 0.06 & 0.59 & 99.48 \\
Co(3)/MS & 77.20 & 22.36 & 0.44 & 0.52 & \\
\hline
\end{tabular}

Table 3. The selectivity of the catalysts on the hydrocracking liquid products

\begin{tabular}{cccc}
\hline \multirow{2}{*}{ Catalyst } & \multicolumn{3}{c}{ Liquid product fraction selectivity (wt.\%) } \\
\cline { 2 - 4 } & Gasoline fraction & Diesel fraction & Organic liquid product \\
\hline Co(1)/MS & 43.11 & 21.74 & 11.12 \\
Co(2)/MS & 39.93 & 16.74 & 22.49 \\
Co(3)/MS & 38.03 & 19.15 & 20.02 \\
\hline
\end{tabular}


the best performance resulting in the lowest conversion of liquid product of $75.97 \%$, but the highest total of hydrocarbon product with $43.11 \%$ gasoline and $21.74 \%$ diesel fractions.

\section{- ACKNOWLEDGMENTS}

The author thanks Universitas Gadjah Mada for the financial support under the scheme of the RTA research grant 2019 (Contract Number: 3187/UN1/DITLIT/DITLIT/LT/2019).

\section{- REFERENCES}

[1] Raqeeb, M.A., and Bhargavi, R., 2015, Biodiesel production from waste cooking oil, J. Chem. Pharm. Res., 7 (12), 670-681.

[2] Yotsomnuk, P., and Skolpap, W., 2017, Biofuel production from waste virgin coconut oil by hydrocracking over HZSM-5 zeolite, Int. J. Adv. Sci. Eng. Technol., 5 (2), 54-57.

[3] Hafriz, R.S.R.M., Salmiaton, A., Yunus, R., and Taufik-Yap, Y.H., 2018, Green biofuel production via catalytic pyrolysis of waste cooking oil using Malaysian dolomite catalyst, Bull. Chem. React. Eng. Catal., 13 (3), 489-501.

[4] Obidike, L.I., 2016, Biofuel production from waste animal fat using pyrolysis (thermal cracking), Thesis, Faculty of Engineering and the Built Environment, University of the Witwatersrand.

[5] Alvarez-Galvan, M.C., Campos-Martin, J.M., and Fierro, J.L.G., 2019, Transition metal phosphides for the catalytic hydrodeoxygenation of waste oils into green diesel, Catalysts, 9 (3), 293.

[6] Salim, I., Trisunaryanti, W., and Arryanto, Y., 2016, Hydrocracking of coconut oil into gasoline fraction using $\mathrm{Ni}$ /modified natural zeolite catalyst, Int. J. ChemTech Res., 9 (4), 492-500.

[7] Verma, D., Rana, B.S., Kumar, R., Sibi, M.G., and Sinha, A.K., 2015, Diesel and aviation kerosene with desired aromatics from hydroprocessing of jatropha oil over hydrogenation catalysts supported on hierarchical mesoporous SAPO-11, Appl. Catal., A, 490, 108-116.

[8] Liu, C., Liu, J., Zhou, G., Tian, W., and Rong, L., 2013,
A cleaner process for hydrocracking of jatropha oil into green diesel, J. Taiwan Inst. Chem. Eng., 44 (2), 221-227.

[9] Ahmed, S., Ali, S.A., Hamid, H., and Honna, K., 2003, Preparation, characterization, and catalytic evaluation of first stage hydrocracking catalyst, Stud. Surf. Sci. Catal., 145, 295-298.

[10] Trisunaryanti, W., Falah, I.I., Prihandini, D.R., and Marsuki, M.F., 2019, Synthesis of Ni/mesoporous silica-alumina using Sidoarjo mud and bovine bone gelatin template for hydrocracking of waste lubricant, Rasayan J. Chem., 12 (3), 1523-1529.

[11] Trisunaryanti, W., Triyono, and Fatmawati, D.A., 2020, Synthesis of $\mathrm{Co}-\mathrm{NH}_{2} /$ mesoporous silica bifunctional catalyst using Sidoarjo mud and bovine bone gelatin template for conversion of used cooking oil into biofuel, Rasayan J. Chem., 13 (1), 723-732.

[12] Trisunaryanti, W., Triyono, Paramesti, C., Larasati, S., Santoso, N.R., and Fatmawati, D.A., 2020, Synthesis and characterization of Ni$\mathrm{NH}_{2} /$ mesoporous silica catalyst from Lapindo mud for hydrocracking of waste cooking oil into biofuel, Rasayan J. Chem., 13 (3), 1386-1393.

[13] Masykuroh, A., Trisunaryanti, W., Falah, I.I., and Sutarno, 2016, Preparation and characterization of Co and Co-Mo loaded on mesoporous silica for hydrocracking of waste lubricant, Int. J. ChemTech Res., 9 (9), 598-606.

[14] Triyono, Trisunaryanti, W., Putri, A.D., Lutfiana, A., and Dewi, K., 2018, Transesterification of waste cooking oil using $\mathrm{NH}_{2} / \mathrm{MCM}-41$ base catalyst: effect of methanol/oil mole ratio and catalyst/oil weight ratio towards conversion of ester, Asian J. Chem., 30 (5), 953-957.

[15] Meléndez-Ortiz, H.I., Mercado-Silva, A., GarcíaCerda, L.A., Castruita, G., and Perera-Mercado, Y.A., 2013, Hydrothermal synthesis of mesoporous silica MCM-41 using commercial hydrothermal synthesis of mesoporous silica MCM-41 using commercial sodium silicate, J. Mex. Chem. Soc., 57 (2), 73-79.

[16] Parapat, R.Y., Saputra, O.H.I., Ang, A.P., Schwarze, M., and Schomäcker, R., 2014, Support effect in the 
preparation of supported metal catalysts via microemulsion, RSC Adv., 4 (92), 50955-50963.

[17] Prasiwi, A.D., Trisunaryanti, W., Tiyono, Falah, I.I., Santi, D., and Marsuki, M.F., 2019, Synthesis of mesoporous carbon from Merbau wood (Intsia spp.) by microwave method as $\mathrm{Ni}$ catalyst support for $\alpha$ cellulose hydrocracking, Indones. J. Chem., 19 (3), 575-582.

[18] Marsuki, M.F., Trisunaryanti, W., Falah, I.I., and Wijaya, K., 2018, Synthesis of Co, Mo, Co-Mo and Mo-Co catalysts, supported on mesoporous silicaalumina for hydrocracking of a-cellulose pyrolysis oil, Orient. J. Chem., 34 (2), 955-962.

[19] Li, S., Li, X., Wu, H., Sun, X., Gu, F., Zhang, L., He, H., and Li, L., 2019, Mechanism of synergistic effect on electron transfer over Co-Ce/MCM-48 during ozonation of pharmaceuticals in water, ACS Appl. Mater. Interfaces, 11 (27), 23957-23971.

[20] Behniafar, H., Yazdi, M., Farshad, S., and Malekshahinezhad, K., 2016, Poly(4,40oxydiphenylene-pyromellitimide) loaded by $\mathrm{NH}_{2}-$ functionalized silica: Optical and thermal behavior of new polyimide-based nanocomposites, High Perform. Polym., 28 (10), 1228-1234.

[21] Trisunaryanti, W., Triyono, Falah, I.I., Siagian, A.D., and Marsuki, M.F., 2018, Synthesis of Cemesoporous silica catalyst and its lifetime determination for the hydrocracking of waste lubricant, Indones. J. Chem., 18 (3), 441-447. 